Article

\title{
Polar Sea Ice Monitoring Using HY-2A Scatterometer Measurements
}

\author{
Mingming Li ${ }^{1, *}$, Chaofang Zhao ${ }^{1,2, *}$, Yong Zhao ${ }^{1}$, Zhixiong Wang ${ }^{1}$ and Lijian Shi ${ }^{3,4}$ \\ 1 \\ Department of Marine Technology, College of Information Science and Engineering, Ocean University of China, \\ Qingdao 266100, China; zhao.alcide@gmail.com (Y.Z.); ylwzx2007@163.com (Z.W.) \\ 2 Laboratory for Regional Oceanography and Numerical Modeling, Qingdao National Laboratory for Marine \\ Science and Technology, Qingdao 266100, China \\ 3 National Satellite Ocean Application Service, State Oceanic Administration, Beijing 100081, China; \\ shilj@mail.nsoas.org.cn \\ 4 Key Laboratory of Space Ocean Remote Sensing and Application, State Oceanic Administration, \\ Beijing 100081, China \\ * Correspondence: orsi2014@126.com (M.L.); zhaocf@ouc.edu.cn (C.Z.); Tel.: +86-532-6678-2949 (C.Z.) \\ Academic Editors: Walt Meier, Mark Tschudi, Xiaofeng Li and Prasad S. Thenkabail \\ Received: 25 April 2016; Accepted: 17 August 2016; Published: 22 August 2016
}

\begin{abstract}
A sea ice detection algorithm based on Fisher's linear discriminant analysis is developed to segment sea ice and open water for the Ku-band scatterometer onboard the China's Hai Yang 2A Satellite (HY-2A/SCAT). Residual classification errors are reduced through image erosion/dilation techniques and sea ice growth/retreat constraint methods. The arctic sea-ice-type classification is estimated via a time-dependent threshold derived from the annual backscatter trends based on previous HY-2A/SCAT derived sea ice extent. The extent and edge of the sea ice obtained in this study is compared with the Special Sensor Microwave Imager/Sounder (SSMIS) sea ice concentration data and the Sentinel-1 SAR imagery for verification, respectively. Meanwhile, the classified sea ice type is compared with a multi-sensor sea ice type product based on data from the Advanced Scatterometer (ASCAT) and SSMIS. Results show that HY-2A/SCAT is powerful in providing sea ice extent and type information, while differences in the sensitivities of active/passive products are found. In addition, HY-2A/SCAT derived sea ice products are also proved to be valuable complements for existing polar sea ice data products.
\end{abstract}

Keywords: HY-2A/SCAT; sea ice extent; sea ice type; Arctic; Antarctic

\section{Introduction}

Sea ice, acting as one of the critical components of the global climate system, modulates atmospheric and oceanic circulations through affecting ocean surface radiation, temperature, energy balance, and the circulation of salt flow [1]. The polar sea ice accounts for a large proportion of global sea ice, therefore, the study of the spatial and temporal properties of polar sea ice is of great significance for monitoring global climate changes, weather forecast, fishing conditions and marine transportation. In the past few decades, the development of satellite remote sensing techniques has provided new solutions and valuable data for monitoring the vast expanse of sea ice in the polar region. The satellite scatterometer, which is able to measure the backscatter characteristics of surface coverage, has been verified as a useful tool for polar sea ice monitoring, for example, sea ice extent [2,3] and type [4-6] related studies.

In 1997, Remund and Long developed an automatic sea ice and open water discrimination algorithm using Ku-Band data derived from NASA Scatterometer (NSCAT) [7,8]. Their principles were later adopted by the French Institute of Research for the Exploitation of the Sea (IFREMER) 
and Norwegian Meteorological Institute [9] for the development of similar sea ice discrimination algorithms using QuikSCAT data. The technique, known as the Remund/Long-NSCAT (RL-N) algorithm, distinguishes between sea ice and open water by contrasting the azimuthal and polarization dependence properties of sea ice and open water surface backscatters using an iterative maximum-likelihood method [8,10,11]. What should be noted is that the accuracy of the RL-N algorithm can be considerably affected by wind-induced roughness surface and the melt of summer ice [12].Fortunately, this problem is solved by binary image processing techniques and sea ice growth/retreat constraint methods [3]. The RL-N was employed by National Environmental Satellite Data and Information Service (NESDIS) and NOAA's National Environmental Satellite Data for the release of the QuikSCAT and Oceansat-2 Scatterometer (OSCAT) BUFR geophysical products.

As part of the Ocean and Sea Ice Satellite Application Facility (OSI SAF), created by European Organization for the Exploitation of Meteorological Satellites (EUMETSAT), the Royal Netherlands Meteorological Institute (KNMI) developed a new Bayesian algorithm for sea ice detection using C-Band European Space Agency Remote Sensing Satellite (ERS) [13]. The KNMI algorithm is based on the probabilistic distances to ocean wind and sea ice geophysical model functions. Later, this algorithm was improved to detect sea ice using QuikSCAT data [14,15]. Today, a modified version of the algorithm using C-band scatterometer data from ASCAT is the basis of the OSI SAF operational near-real time sea ice products $[16,17]$. The key difference between RL-N and KNMI sea ice detection algorithms is that the former ice and sea cluster centroids in the 4-D hyperspace of $\left[\sigma_{V} / \sigma_{H}, \sigma_{H}, \Delta \sigma_{H}, \Delta \sigma_{V}\right]$ combinations are replaced by actual ice and ocean geophysical model functions in the original space of QuikSCAT backscatter quadruplets $\left[\left(\sigma_{H}, \sigma_{V}\right)_{a f t},\left(\sigma_{H}, \sigma_{V}\right)_{\text {fore }}\right]$ in KNMI developed algorithm. The aforementioned parameters $\sigma_{V}$ and $\sigma_{H}$ are the vertical and horizontal polarization backscatter coefficient, respectively, and the $\Delta \sigma_{H, V}$ denotes the standard deviations of the errors in horizontal and vertical polarization backscatter coefficients. In addition, the sea surface temperature filter is added in the KNMI algorithm to weaken error caused by occasional erratic winds over sea ice surface.

The sea ice type classification was developed by Kwok (2004) [4] using a fixed threshold of Ku-band backscatters obtained from the QuikSCAT instrument aboard SeaWinds, and the threshold is optimally obtained by collocating high-resolution RADARSAT SAR imagery. In 2006, Nghiem [18] classified the seasonal ice and perennial ice based on statistical analysis of backscatter signatures. In 2014, Swan and Long [5] developed a seasonally varying threshold to classify first-year (FY) and multiyear (MY) ice during the winter using a seven-year (2003-2009) mean of vertical polarization backscatter trends observed by QuikSCAT, and a decrease in MY sea ice was found by validating their results against Canadian Ice Service (CIS) charts. Following the 2003-2009 QuikSCAT sea ice type records completed by Swan and Long [5], Lindell and Long [6] estimated the sea ice type using QuikSCAT and OSCAT observations based on the threshold of $40 \%$ NASA team ice concentration data. They also corrected the misclassifications that FY ice is improperly classified as MY ice in the marginal ice zone (MIZ), because of high radar backscatter in MIZ caused by the incursion of ocean waves and swells [9]. As OSCAT no longer provides operational data since 2014 and in order to extend the scatterometer ice type classification data records beyond 2014, Lindell and Long (2016) [19] developed a Bayesian estimator to classify the Arctic sea ice using the ASCAT and SSMIS data. Despite the continuous development of the polar sea ice type classification techniques, all aforementioned research focused on the Arctic, since the Arctic Ocean is relatively land-locked, allowing extensive multiyear ice to form through the perennial accumulation. In contrast, the Antarctic sea ice, which is surrounded by open water, forms mostly within one year and does not have clear segmentation distribution mode between MY and FY ice in recent years.

The first Chinese HY-2A/SCAT has been operationally producing data products since October 2011, and the data have been successfully applied into many aspects of climate and weather related studies $[20,21]$. However, its potential in polar sea ice monitoring and related studies need to be investigated. Therefore, this paper discusses the implementation of HY-2A/SCAT data in polar sea ice extent mapping and Arctic sea ice type identification, and to provide a verification data set for other 
active/passive microwave sensors derived sea ice products. This paper is organized as follows: the experimental data and preprocessing are described in Section 2. Section 3 describes the HY-2A/SCAT data parameters and their levels of sensitivity to the presence of sea ice. The algorithm and validation of sea ice-ocean discrimination is described in Section 4. Section 5 provides the method and validation of Arctic sea ice type, and Section 6 concludes.

\section{Data Sources and Preprocessing}

The HY-2A satellite, launched in 16 August 2011, is China's first satellite with all weather and 24-hour capabilities of observing ocean dynamic environment parameters. HY-2A shares a similar sun-synchronous near polar orbit with an orbital inclinations of $99.34^{\circ}$ at $971 \mathrm{~km}$. In a first stage, its repeat cycle is 14 days with an intersection period of $104.46 \mathrm{~min}$, and it runs $13+11 / 14$ revolutions every day. In a second stage it will cover 13+131/168 revolutions every day with the repeat cycle of 168 days. Figure 1 shows the daily coverage of the HY-2A/SCAT products in the first stage. The scatterometer onboard the HY-2A satellite (hereafter referred to as HY-2A/SCAT) employs a rotating pencil beam antenna which transmits and receives at $13.256 \mathrm{GHz}$ observation of the backscatter cross section $\left(\sigma_{H}^{41}, \sigma_{V}^{48}\right)$ are collected in horizontally polarized $(\mathrm{HH})$ inner beam and vertically polarized (VV) outer beam at incidence angles of $41^{\circ}$ and $48^{\circ}$, respectively. The H-polarization covers a swath of $1350 \mathrm{~km}$, while V-polarization coverage swath is $1700 \mathrm{~km}$. The backscatter from VV is used in this study for ice type classification, while $\mathrm{HH}$ and VV backscatters are used to extract parameters for sea ice and open water discrimination.

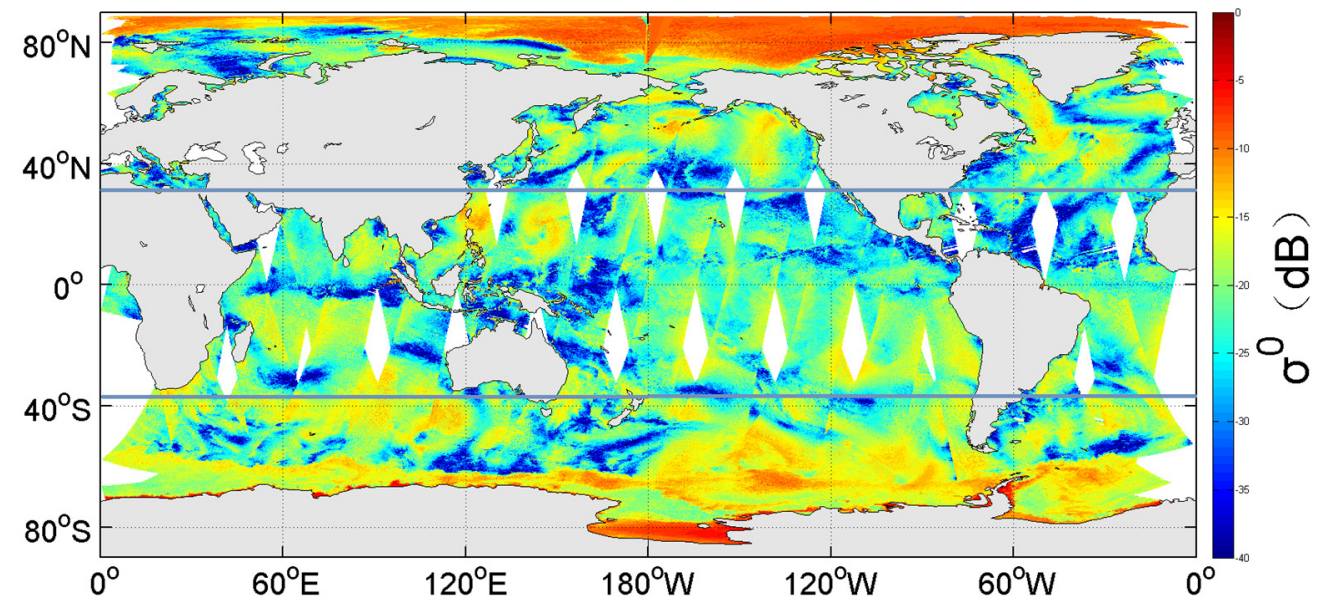

Figure 1. The daily global coverage of HY-2A/SCAT $\sigma^{0}$ from the 20 September 2013.

NASA and the National Snow and Ice Data Center (NSIDC) specified a projection plane or grid tangent to Earth's surface at 70 degree northern and southern latitude with little or no distortion in the MIZ [22,23]. This projection plane was defined by $448 \times 304$ and $332 \times 316$ grid points in Arctic and Antarctic using polar stereographic projection formula, respectively. Based on this projection, HY-2A/SCAT daily $\sigma^{0}$ measurements of the polar region (latitude higher than $30.98^{\circ} \mathrm{N}$ and $39.23^{\circ} \mathrm{S}$, respectively, see the horizontal latitude line in Figure 1) are resampled into $25 \mathrm{~km}$ resolution polar plane, see Figure 2. After resampling, the count of valid $\sigma^{0}$ observation per pixel per day ranges from 0 to 40 , while the counts of $\sigma^{0}$ observations per grid per day are mainly concentrated in the range of 1-15 and 2-25 for the Arctic and Antarctic region, respectively. In addition, because the Arctic and Antarctic sea ice distribute mainly at the latitude belt that has the highest counts of $\sigma^{0}$ observations, it is reasonable to detect polar sea ice using the daily HY-2A/SCAT data. For every single polarization image in Section 3, the average of multiple measurements in a pixel is assigned to that pixel. 


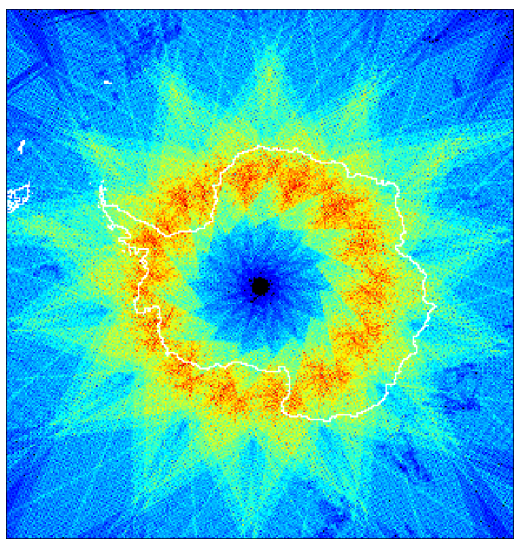

(a)

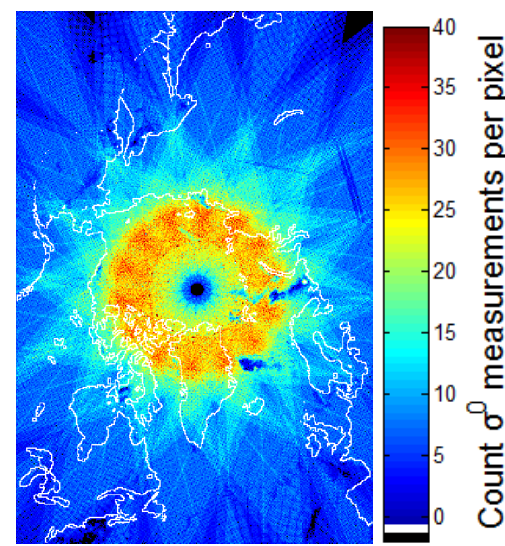

(b)

Figure 2. HY-2A/SCAT $\sigma^{0}$ count distribution in (a) Antarctic and (b) Arctic on 20 September 2013. The black area represents for no observation and the white lines is coastline, while other colors are count of $\sigma^{0}$ measurements per pixel.

\section{HY-2A Sea Ice Mapping Parameters}

In 1997, the Seasat-A scatterometer dual-polarized ratio was initially used to discriminate sea ice from open water [11]. This polarization ratio reacts to the backscatter differences of polarization and incidence angle between sea ice and open water. In general, microwave signatures of sea ice are typically more isotropic in incidence angle than that of the sea water surfaces [3]. Based on this physical mechanism, experiments were designed to test the sensitivity of HY-2A/SCAT dual-polarized ratio $\left(\sigma_{V}^{48} / \sigma_{H}^{41}\right)$ to the sea ice and the ocean. Results show that $\sigma_{V}^{48} / \sigma_{H}^{41}$ is low for sea ice region and relatively higher for open water. However, wind-induced surface roughness can potentially cause open water with low polarization ratio close to sea ice [10]. In order to overcome this problem, the dual-polarized measurements $\left(\sigma_{H}^{41}, \sigma_{V}^{48}\right)$ and their daily standard deviations $\left(\Delta \sigma_{H}^{41}, \Delta \sigma_{V}^{48}\right)$ are combined for monitoring sea ice.

As for the dual-polarized measurements, the HY-2A/SCAT h-pol measurements $\left(\sigma_{H}^{41}\right)$ have similar signatures with their v-pol counterparts over sea ice, but are much lower compared with v-pol measurements $\left(\sigma_{V}^{48}\right)$ over the open water. Therefore, the $\sigma_{H}^{41}$ signatures of sea ice and open water are more easily segmented and used for sea ice-water discrimination. Meanwhile, we find that the V-pol $\sigma^{0}$ trends of HY-2A/SCAT have greater discrepancies between the MY and FY ice by examining the statistics of annual backscatter trends. Thus the v-pol measurements $\left(\sigma_{V}^{48}\right)$ are used to identify sea ice types.

The daily standard deviation $\left(\Delta \sigma_{H}^{41}, \Delta \sigma_{V}^{48}\right)$ carries information of the azimuthal and temporal differences of surface backscatter $[3,24,25]$. For azimuthal information, the isotropy of sea ice results in lower changes in different observation directions compared with the open water. Thus, this parameter can also be used to distinguish the sea ice from the open water which has large variations in $\Delta \sigma_{H, V}$. For temporal information, it should be noted that the changes in the collection time of the track data cause the standard deviation to rise, and this contributes to the variation of $\Delta \sigma_{H}^{41}$ both in sea ice and ocean regions. Although the significance of such contributions is unclear, it does not affect the utility of this parameter in sea ice and open water discrimination.

In this study, all discussed parameters derived from the HY-2A/SCAT are adopted for sea ice monitoring. Example images of these parameters on 20 September 2013 are shown in Figure 3, in which the central continent mask is obtained from NSIDC. Figure 3a shows the image of $\sigma_{V}^{48} / \sigma_{H}^{41}$, it is clear that $\sigma_{V}^{48} / \sigma_{H}^{41}$ is much lower in sea ice regions compared with the open water as expected. From Figure $3 \mathrm{~b}, \mathrm{c}$, the images of $\sigma_{H}^{41}$ and $\sigma_{V}^{48}$ respectively, the sea ice can be easily distinguished from the open water since values of them are much higher over the sea ice region. Finally, from Figure 3d,e, high variability of the $\Delta \sigma_{H}^{41}$ and $\Delta \sigma_{V}^{48}$ over open water regions could be clearly seen while 
this parameter for the sea ice region is quite steady. It should be noted that the pixels with less than two $\mathrm{HH}$ and VV measurements are regarded as bad pixels that cannot be used to discriminate sea ice from the ocean. Consequently, we use the previous day's good data to replace the bad pixels in order to achieve full daily sea ice extent.

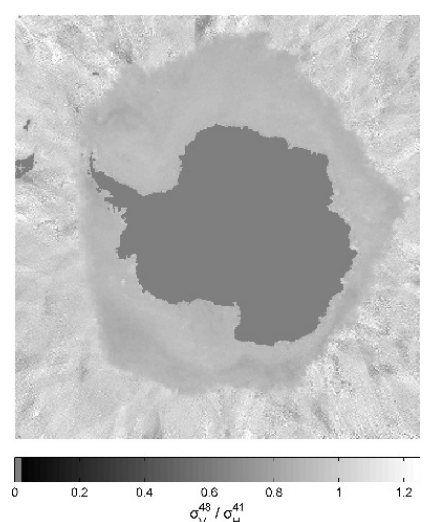

(a)

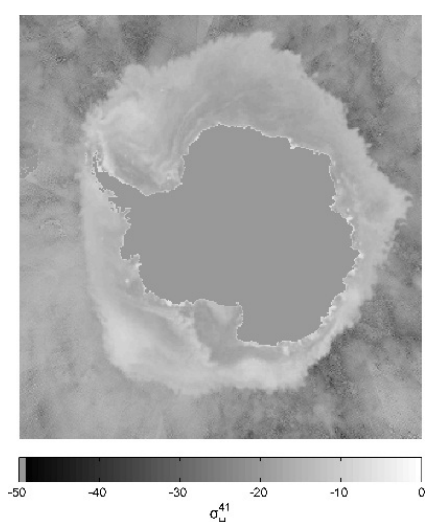

(b)

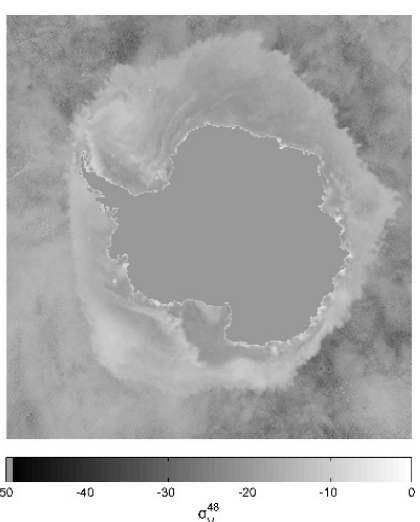

(c)

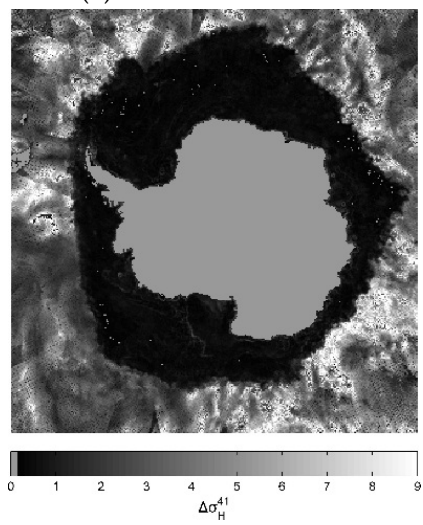

(d)

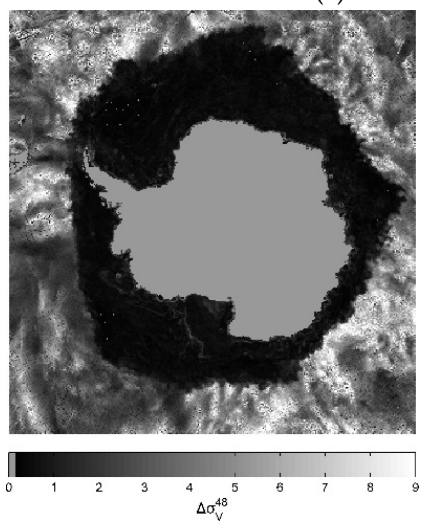

(e)

Figure 3. The mapping parameter images of (a) $\sigma_{V}^{48} / \sigma_{H}^{41},(\mathbf{b}) \sigma_{H}^{41},(\mathbf{c}) \sigma_{V}^{48},(\mathbf{d}) \Delta \sigma_{H}^{41}$ and (e) $\Delta \sigma_{V}^{48}$ on 20 September 2013. Antarctic images contain $332 \times 316$ pixels with a pixel resolution of $25 \mathrm{~km}$, and its central area for land.

\section{Sea Ice Extent Mapping}

\subsection{FLDA Sea Ice-water Discrimination Method}

After parameter selection, the combined 4-D hyperspace parameter matrix $\left(\sigma_{V}^{48} / \sigma_{H}^{41}, \sigma_{H}^{41}, \Delta \sigma_{H}^{41}, \Delta \sigma_{V}^{48}\right)$ is adopted to distinguish between sea ice and ocean using the Fisher's Linear Discriminant Analysis (FLDA) method. The FLDA [26-28] classifier is achieved through extracting the 4-D hyperspace parameters of the sea ice and the open water, and then searching an optimal projection axes on which samples of the sea ice and the open water could be differentiated easily while the data samples belonging to the same class are highly centralized.

For the extraction of HY-2A/SCAT sample parameters, a 5\% threshold on a NASA Team ice concentration product produced using the Special Sensor Microwave Imager/Sounder (SSMIS) is used to determine the sea ice extent, and the open water extent is known in the SSMIS ice concentration data [29] obtained from the NSIDC. Assuming that there are $\mathrm{n}$ extracted samples with d dimensions which are classified to sea ice-water, and are named $x_{1}, \ldots, x_{n} \in R^{d}$. Let $n_{1}$ of the $\mathrm{n}$ samples belong to sea ice $\omega_{1}$, and $n_{2}$, the rest portion of the $n$ samples, belongs to ocean $\omega_{2}$. The mean of each sample class $\mu_{i}(i=1,2)$ and the mean of the overall ice-ocean samples $\mu$ could be calculated using Equations (1) and (2), respectively. 


$$
\begin{gathered}
\mu_{i}=\frac{1}{n_{i}} \sum_{x \in \omega_{i}} x \quad i=1,2 \\
\mu=\frac{1}{n} \sum_{i=1}^{n} x_{i}
\end{gathered}
$$

The infra-class dispersion matrix $S_{b}$ and the inter-class dispersion matrix $S_{w}$ of sea ice and open water are shown as follows:

$$
\begin{gathered}
S_{b}=\sum_{i=1}^{2} p(i)\left(\mu_{i}-\mu\right)\left(\mu_{i}-\mu\right)^{T} \\
S_{w}=\sum_{i=1}^{2} \frac{1}{n} \sum_{x \in \omega_{i}}\left(x-\mu_{i}\right)\left(x-\mu_{i}\right)^{T}
\end{gathered}
$$

where $p(i)=n_{i} / n, i=1,2$. In order to search for the optimal projection axes, Fisher's criterion is employed to seek a hyperplane $\varphi$ to maximize $\frac{\varphi^{T} S_{b} \varphi}{\varphi^{T} S_{w} \varphi}$ and optimally segment sea ice and open water [27]. The $\varphi$ is explicitly given by Equation (5).

$$
\varphi=S_{w}^{-1} S_{b}
$$

The optimal projection vector is obtained by solving a general eigenvalue problem as the eigenvector corresponding to the largest eigenvalue of the matrix $S_{w}^{-1} S_{b}$. After obtaining the projection vector, the four parameters are projected to a 1-dimensional linear space. The distribution center of the sea ice and open water in the 1-dimensional space are then calculated. Finally, for each unclassified pixel, its distances referring to the distribution centers of the sea ice and open water samples are computed, and the pixel is classified to the class with relatively shorter distance. The polar sea ice extent obtained using the HY-2A/SCAT is shown in Figure 4a. The sea ice extent is apparent, yet errors still exist. Therefore, the residual error filtering is employed to improve the results of the classification using FLDA algorithm.

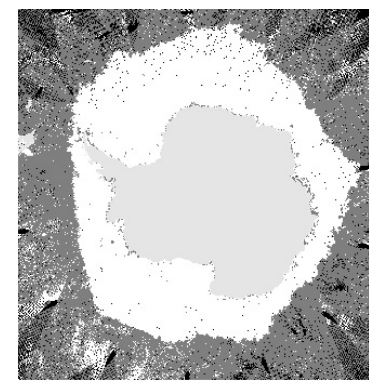

(a)

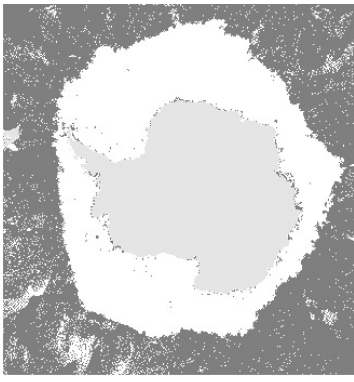

(b)

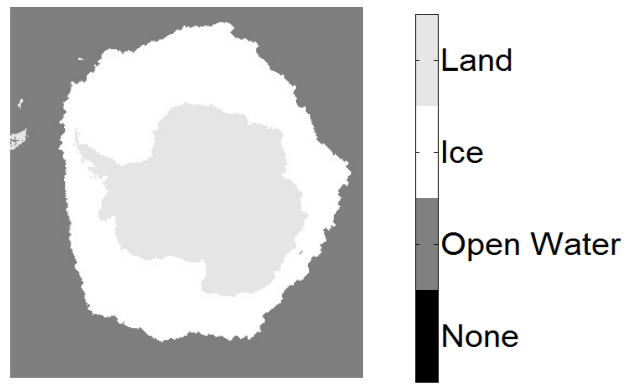

(c)

Figure 4. The gray images of Antarctic sea ice in 20 September 2013 through discrete steps (its central area is land): (a) FLDA discrimination with some portions of no observation and invalid parameters (black pixels); (b) black portion (in (a)) elimination dependent on the previous day's HY-2A/SCAT data; (c) misclassification reduction by region growing and dilation/erosion techniques.

\subsection{Residual Errors Reduction}

Occasionally, the afore-introduced parameters are invalid, because of the existence of non-observation regions and insufficient $\mathrm{HH}$ or VV observations (less than two observations), see the black region in Figure 4a. In order to operationally obtain daily HY-2A/SCAT sea ice extent, the pixels where the parameters are invalid are replaced using the previous day's products. The resolved result of Fig 4a is shown in Figure 4b, although there still have errors after remediation, significant improvements can be clearly found comparing with the result shown in Figure 4a. 
It is possible that the ocean might be classified as sea ice because of the occurrence of strong sea surface winds, and the other physical mechanisms may also cause sea ice to be misclassified as ocean. These errors occur in the form of patch or isolated pixels during the imaging period as shown in Figure $4 b$, and the former is much more common than the latter. Fortunately, image erosion/dilation technique and sea ice growth/retreat constraint methods could be utilized to eliminate such misclassification. Specifically: the region growing technique [30] is used to identify and remove the misclassified as open water patches within sea ice region and vice versa. It is worth noting the existence of ice-free polynyas within sea ice region. In order to objectively identify the total sea ice extent, this processing can be adjusted to retain polynyas along with the infrequent misclassifications within the ice pack by skipping the inverse region growing step. In addition, the observed errors of infrequent misclassified "indentation" or "extrusions" along the ice edge are solved by image erosion/dilation method [31]. To select suitable structure element radius of image dilation/erosion, the previous day's ice extent map is combined with typical sea ice growth and retreat rates to constrain allowable ice motion. For this study, a threshold of $100 \mathrm{~km}$ per day is chosen as the maximum edge motion speed and is consistent with the radius of 2 mask at $25 \mathrm{~km}$ resolution image. Thus, diamond structure elements with a radius of 2 grid pixels is adopted to perform primarily image dilation/erosion to eliminate the errors in the sea ice edge. The result after above processing of Figure $4 \mathrm{~b}$ is shown in Figure 4c. Almost all of the unreasonable classifications are corrected in both the connected sea ice and open water regions.

\subsection{Sea Ice Mapping and Validation}

As discussed above, the FLDA algorithm is employed to produce operationally daily HY-2A/SCAT polar sea ice extent imagery. Figure 5 shows the seasonal and geographical sea ice products for a limited subset of days. The sea ice extent in the Arctic is shown in the top panel of Figure 5. The variations of the sea ice extent in the maximum extent, the ice ablation phase, the summer minimum and the growth period, revealing the dynamic nature of arctic sea ice throughout the seasonal cycle, could be clearly seen from the image sequence. In the Antarctic, shown the summer minimum, the growth period, the maximum extent and the melt parse of the Antarctic polar sea ice could also be clearly observed, which similarly demonstrates the seasonal variations of the ice pack.

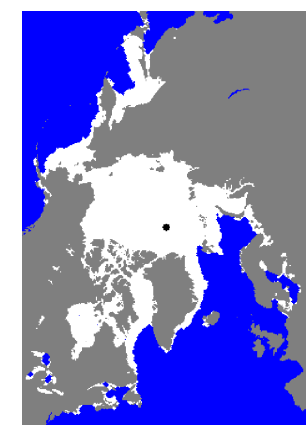

7 March 2013

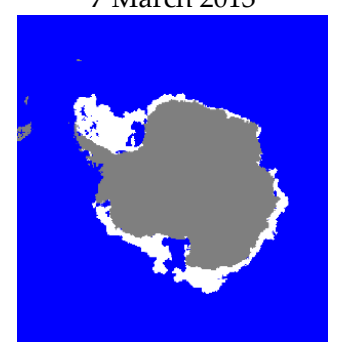

25 Feburary 2013

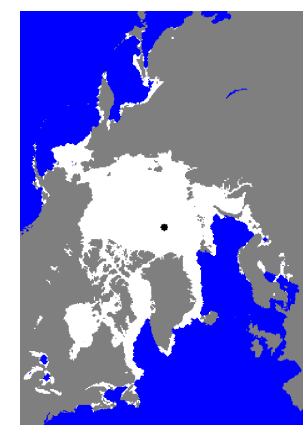

4 May 2013

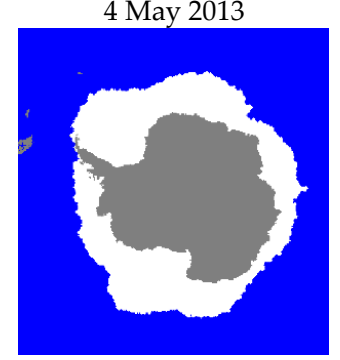

15 Jun 2013

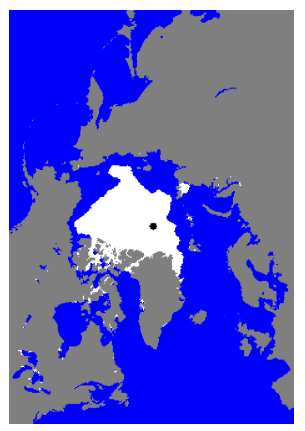

16 September 2013

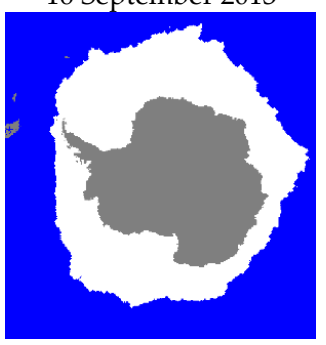

25 September 2013

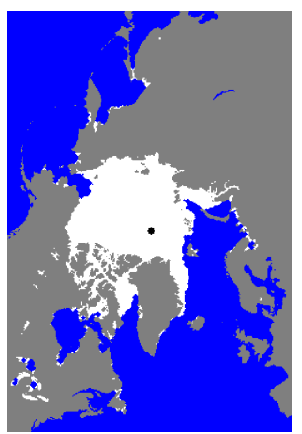

15 November 2013

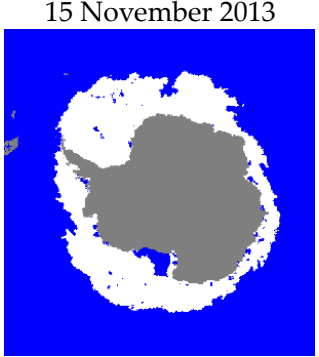

16 December 2013

None

Open Water

Sea Ice

Land

Figure 5. Example daily Polar sea ice extent from HY2-SCAT. 


\subsubsection{SSMIS Sea Ice Concentration Comparison}

As one of the common validation datasets, the continuous series of daily sea ice concentrations generated by NASA Team algorithms using SSMIS (DMSP F17) brightness temperatures from NSIDC in circumpolar regions [29] are adopted to verify HY-2A/SCAT derived sea ice extent. The SSMIS ice concentration and HY-2A/SCAT sea ice extent images are projected using the same polar stereographic projections and are presented using the same resolution grid with a pixel spacing of $25 \mathrm{~km}$. Then, the HY-2A/SCAT sea ice extent is compared with different ice extents at various SSMIS ice concentration levels. Past research has indicated that the $15 \%$ ice concentration level is consistent with sea ice extent derived in other studies [32], while SSMIS 30\% ice concentration contour are more consistent with the NSCAT derived sea ice extent [10]. In addition, the $15 \%$ and $30 \%$ SSMIS concentration contours were compared with the QuikSCAT derived ice extent $[3,33]$. This correspondence relationship may change with different sensor and algorithm. In this section, the $0 \%, 15 \%$ and 30\% SSMIS contours are used to make inter-comparison with the HY-2A/SCAT sea ice extent.

The daily HY-2A/SCAT polar sea ice extents and the SSMIS $0 \%, 15 \%$ and 30\% ice extents from 1 January 2013 to 31 July 2015 are shown in Figure 6. Because that the area of the pole hole is a no-data region, it is excluded when making sea ice extent calculation in this section. Figure 6 also shows that the HY-2A/SCAT observed sea ice extent fall into the range from SSMIS 0\% to SSMIS 30\% extent. For the Arctic, we found that the HY-2A/SCAT derived sea ice extent varies more widely between SSMIS $0 \%$ extent and SSMIS 30\% extent, and the HY-2A/SCAT derived sea ice extent is greater than the SSMIS $0 \%$ extent during the ice ablation phase. The results for the Antarctic also demonstrate a reasonably good agreement with the SSMIS $0 \%$ extent during the sea ice melt period and fluctuate between SSMIS $0 \%$ and 15\% extent during other time period. In addition, the observed HY-2A/SCAT derived Arctic sea ice extent varies more evidently than Antarctic between SSMIS 0\% and 30\% contour ice extent. Because some Arctic sea ice with lower concentration at low latitudes is difficult to precisely monitor along with the seasonal change. For instance, Sea ice persists off the eastern of Canada coast which extends south of Newfoundland to 50 degrees north latitude and the western coast of Okhotsk during winter in north latitude 50 degrees. Conversely, Antarctic sea ice completely surrounds the continent in winter, and the differences among different ice concentration contours are relatively small. For clarity, the absolute mean and standard deviation of difference between the SSMIS derived ice extent and the HY-2A/SCAT derived ice extent are calculated, and the statistics are shown in Table 1. In general, as listed in Table 1, the differences between the HY-2A/SCAT derived and the SSMIS 15\% sea ice extent are smallest for both the Arctic and the Antarctic, with an absolute mean of 0.4027 and 0.2112 million $\mathrm{km}^{2}$.

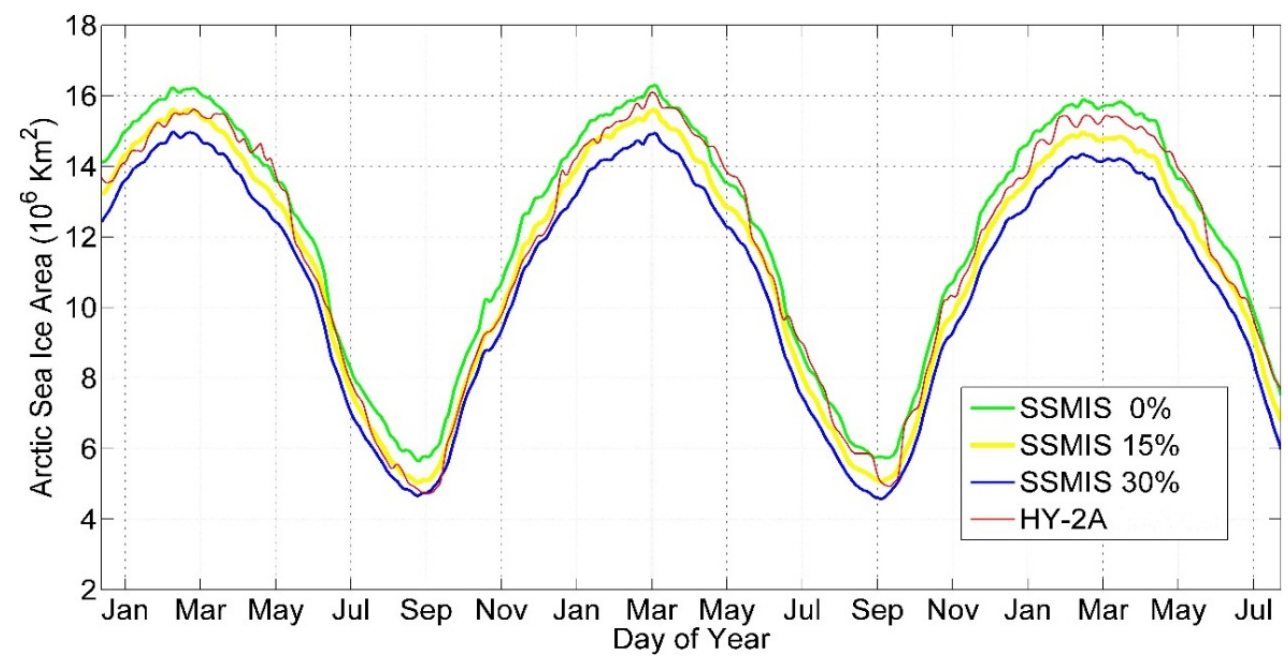

Figure 6. Cont. 


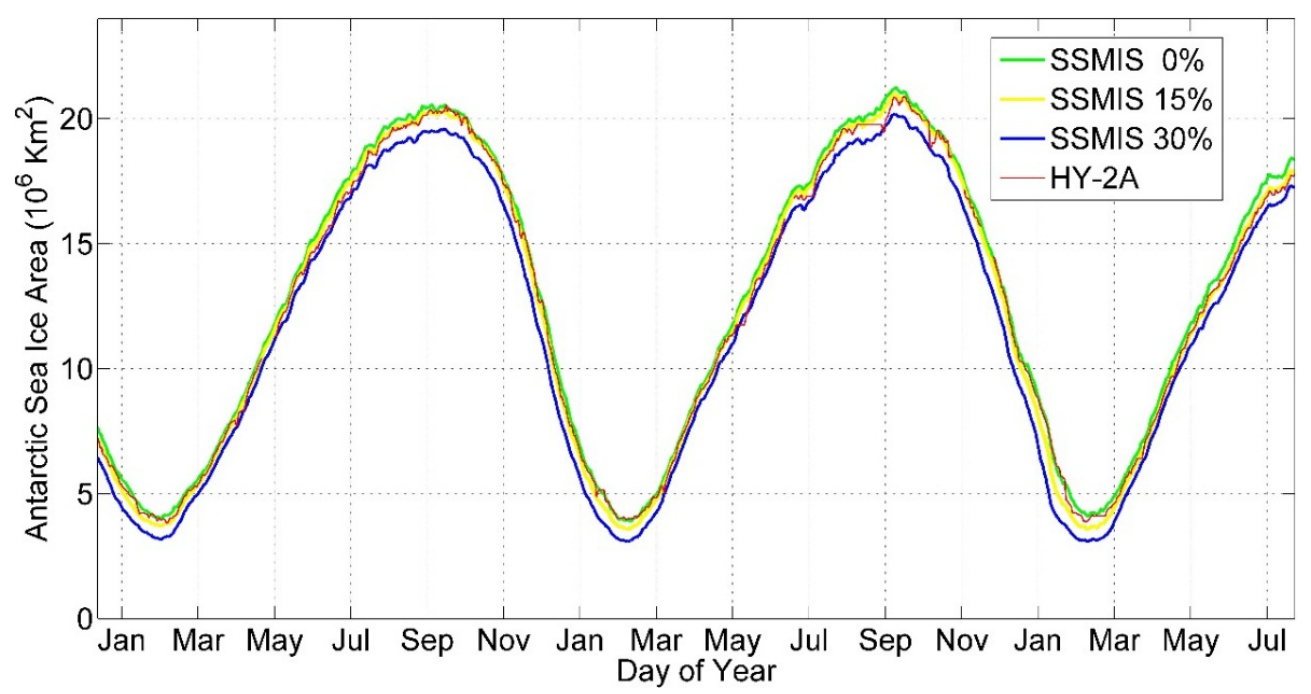

Figure 6. The HY-2A/SCAT and SSMIS 0\%, 15\% and 30\% sea ice extents from January 2013 to July 2015.

Table 1. Statistics of the comparisons between HY-2A and SSMIS $0 \%, 15 \%$ and $30 \%$ sea ice extents.

\begin{tabular}{|c|c|c|c|}
\hline Region & Comparisons & Absolute Mean $\left(10^{6} \mathrm{~km}^{2}\right)$ & Standard Deviation $\left(10^{6} \mathrm{~km}^{2}\right)$ \\
\hline \multirow{3}{*}{ Arctic } & HY-2A and SSMIS $0 \%$ & 0.4959 & 0.2994 \\
\hline & HY-2A and SSMIS 15\% & 0.4027 & 0.2832 \\
\hline & HY-2A and SSMIS 30\% & 0.9082 & 0.4039 \\
\hline \multirow{3}{*}{ Antarctic } & HY-2A and SSMIS $0 \%$ & 0.3045 & 0.2050 \\
\hline & HY-2A and SSMIS 15\% & 0.2122 & 0.1905 \\
\hline & HY-2A and SSMIS 30\% & 0.6841 & 0.3947 \\
\hline
\end{tabular}

In order to further verify sea ice edge, the HY-2A/SCAT-derived edge and SSMIS $0 \%$ and $30 \%$ are superimposed on the image of $\sigma_{H}^{41}$ as shown in Figure 7 . The figure shows that the HY-2A/SCAT-derived sea ice edge generally tracks between SSMIS $0 \%$ and 30\% contours.

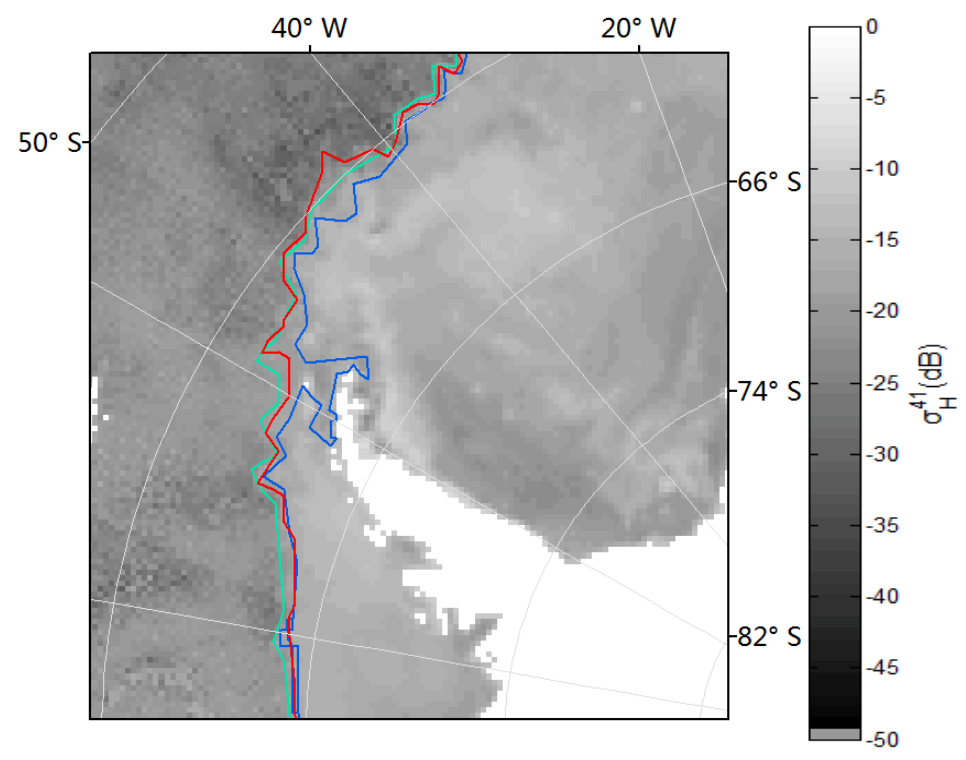

Figure 7. Sea ice edge comparisons in the Weddell Sea quadrant of Antarctica for 20 September 2013. The HY-2A/SCAT ice edge (red), SSMIS NASA Team $0 \%$ and $30 \%$ ice edges are superimposed on the image of $\sigma_{H}^{41}$. 


\subsubsection{RADARSAT SAR Imagery Comparisons}

RADARSAT SAR imagery, with high spatial resolution, is often used to visually validate the sea ice edge in small localized regions. For this study, several 5-m resolution Sentinel-1 h-pol C-band SAR images were obtained from Polar View Website (www.polarview.aq) and are overlapped with HY-2A/SCAT sea ice edges and SSMIS 15\% sea ice concentration contours. The $15 \%$ ice concentration level is chosen because it excludes most of the open ocean background [34] and is consistent with HY-2A/SCAT derived ice extent. Some example images are shown in Figure 8.

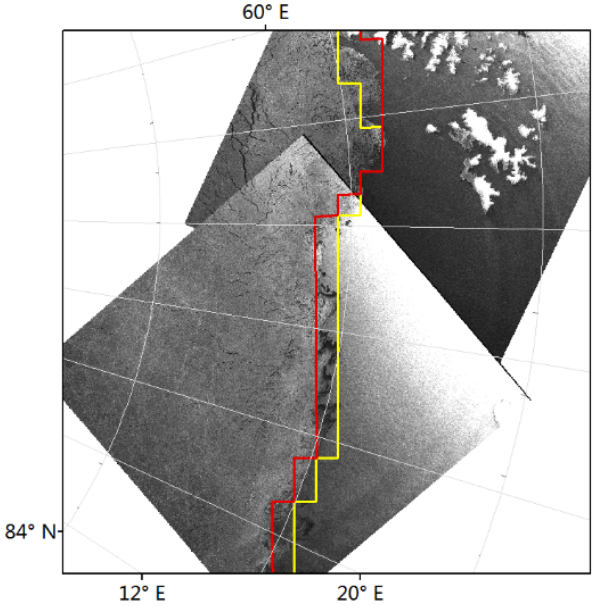

(a)

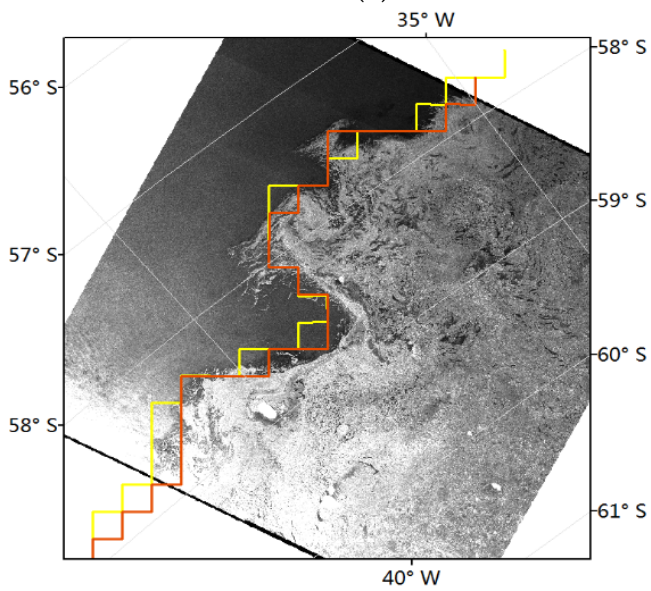

(c)

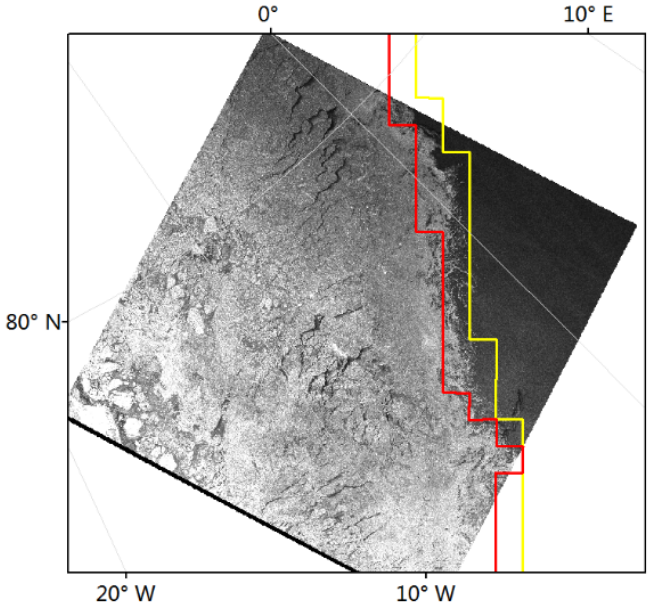

(b)

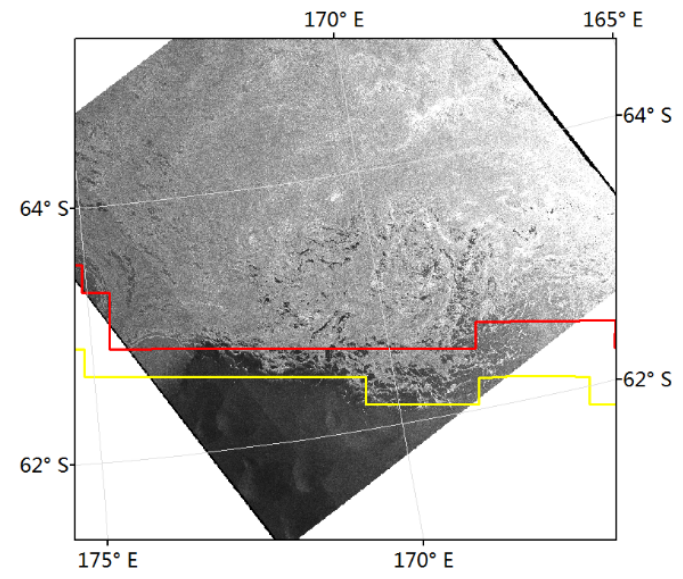

(d)

Figure 8. Sentinel-1 SAR images with HY-2A/SCAT ice edge (red) and SSMIS 15\% sea ice contour edge (yellow) estimates. The acquisition time of the images are: (a) 23 October 2015, (b) 3 November 2015, (c) 29 September 2015 and (d) 20 October 2015.

Figure 8a,b presents the sea ice edge regions near the Greenland on 23 October and 3 November of 2015. Figure 8c,d presents the sea ice edge regions in the Antarctic on 29 September and 20 October of 2015. These examples display the performance of the algorithm under different ice edge conditions. Figure $8 a, c$ shows sharp ice edges, while Figure $8 b$,d shows diffuse ice edges. In general, the observed HY-2A/SCAT edges are well correlated with RADARSAT SAR imagery edges although at a lower resolution. The NASA Team algorithm derived SSMIS edge contours also provide good estimates of the sea ice edge. For sharp sea ice edges, the sea ice edges can be clearly and accurately identified, yet some sea ice are still undetected. Meanwhile, diffuse ice edges with lower sea ice concentrations, can hardly be identified by HY-2A/SCAT. 
We note that the RADARSAT SAR imagery is a "snap-shot" of the ice edge at a particular time of a day, while HY-2A/SCAT edge represents the averages of the entire day, which means that the comparison between the HY-2A/SCAT and the RADARSAT SAR imagery ice edge is not straight forward, but it is still reasonable to conclude that the HY-2A/SCAT derived sea ice using our algorithm is a good reference for monitoring the temporal variation of the sea ice edge.

\section{Temporal Series of Arctic Sea Ice Types}

The sea ice extent are already identified using the HY-2A/SCAT measurements and are proven to be reliable in Section 4. Therefore, we here employ the HY-2A/SCAT derived sea ice extent to classify the HY-2A/SCAT sea ice type, and the sea ice type validation can further prove the objectivity of HY-2A/SCAT derived sea ice extent in magnitude.

\subsection{Ice Types Identification}

As clarified in Section 3, compared to H-pol measurements, the V-pol $\sigma^{0}$ values of HY-2A/SCAT are found to have greater differences between the MY and FY ice. Therefore, the V-pol $\sigma^{0}$ values of HY-2A/SCAT are used mainly in sea ice classification. Understanding the temporal nature of sea ice backscatter allows and improves the classification of sea ice as MY and FY. To visualize temporal sea ice characteristics, the temporal series of the histograms of HY-2A/SCAT $\sigma_{V}^{0}$ over the Arctic sea ice region during the time period of 2012-2015 are generated and are shown in Figure 9. Detailed as follows: the $\sigma_{V}^{0}$ ranging from $-25 \mathrm{~dB}$ to $-5 \mathrm{~dB}$ are normalized at $0.2 \mathrm{~dB}$ intervals bins per day, thus the colors in Figure 9 represent the bin counts of VV measurements per day. Bounds are set subjectively for each day's histogram of winter $\sigma_{V}^{0}$ values (from the October to the following May) by attempting to isolate the area of minimum bin counts that persists for most of the winter. The minimum points between the bounds are then identified by a fifth-degree polynomial, and constitute the time-dependent threshold as shown by the white curves that fluctuates between $-10 \mathrm{~dB}$ and $-15 \mathrm{~dB}$ in Figure 9. As displayed, the distribution from each day during the winter has a large mode around $-10 \mathrm{~dB}$ representing $\mathrm{MY}$ ice and one large mode around $-17 \mathrm{~dB}$ representing FY ice. However, Antarctic sea ice $\sigma_{V}^{0}$ trend as shown in Antarctic 2013-2014 in Figure 9 does not demonstrate a separation of modes corresponding to FY ice and MY ice since there is no much MY ice during the Austral summer.

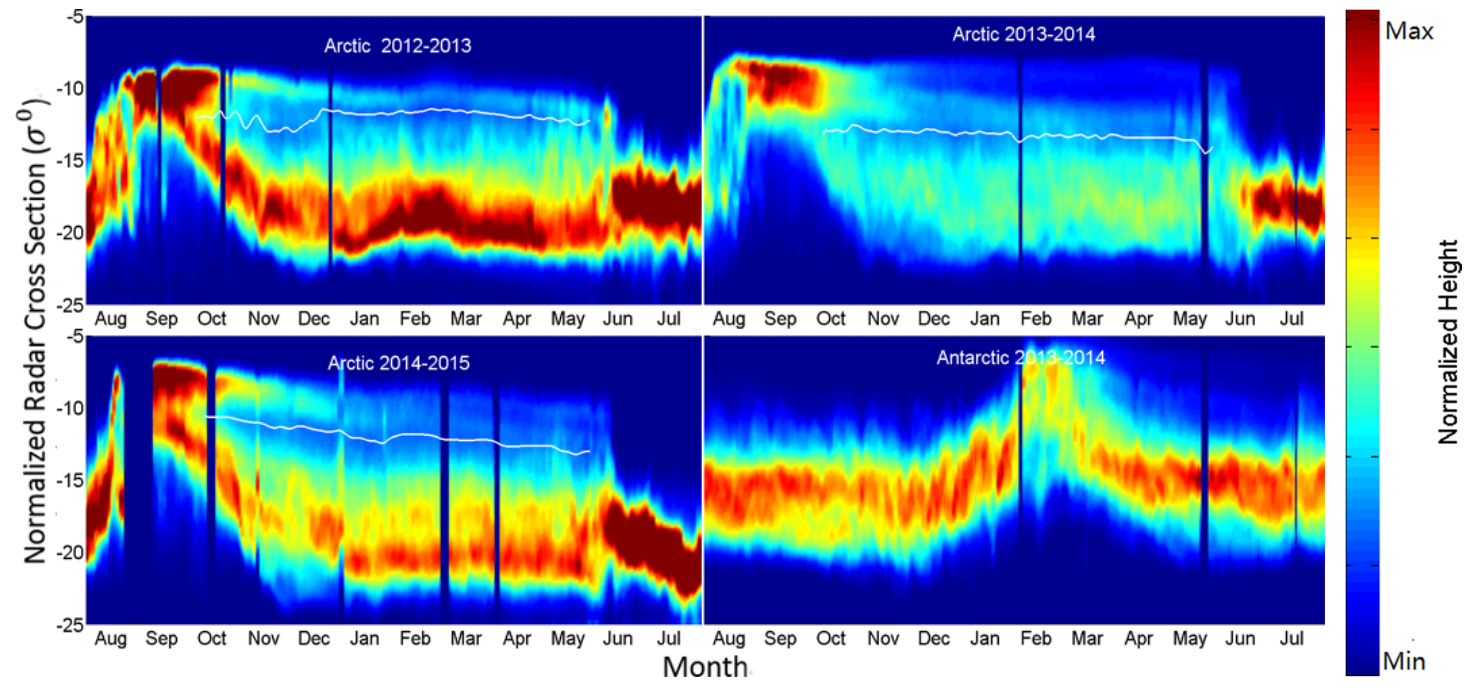

Figure 9. The temporal series of the histograms of HY-2A/SCAT Arctic V-pol $\sigma^{0}$ values for the winter of 2012/2013 (top left), 2013/2014 (top right) and 2014/2015 (bottom left) and Antarctic for the winter of 2013/2014 (bottom right). The Arctic sea ice distribution demonstrates a separation of modes corresponding to FY ice and MY ice, and the white curves are varying thresholds in every winter. Whereas the Antarctic sea ice distribution does not demonstrate such separation. 
Figure 9 also suggests that the microwave signature of FY and MY ice are seasonally dependent: the FY ice $\sigma_{V}^{0}$ drops sharply to lower bounds between September and November. It then decreases slightly from December to the next January. A slight fluctuation at a low value between January and June can be found. After June, it becomes difficult to identify the ice types using the backscatter signal until the late September due to melting. Meanwhile, for MY ice, the backscatter values drop gradually to low values close to that of the FY ice from October to June due to snow accumulation and metamorphic processes [35]. After June, It experienced a slight fluctuation and almost disappeared due to the decrease of the MY in recent decades [5].

Based on this derived daily threshold, the time series of HY-2A/SCAT ice type images on the 15th of each month from January 2013 to July 2015 are produced and shown in Figure 10a. Previous studies indicate that the ice thickness of multiyear ice is thicker than the first-year ice. In general, the Arctic total sea ice presents the phenomenon of the rapid retreat over the past several decade [36]. However, as shown Figure 10a, the observed MY ice area appears to recover somewhat in 2014. Unfortunately, this recover mode does not last in 2015.

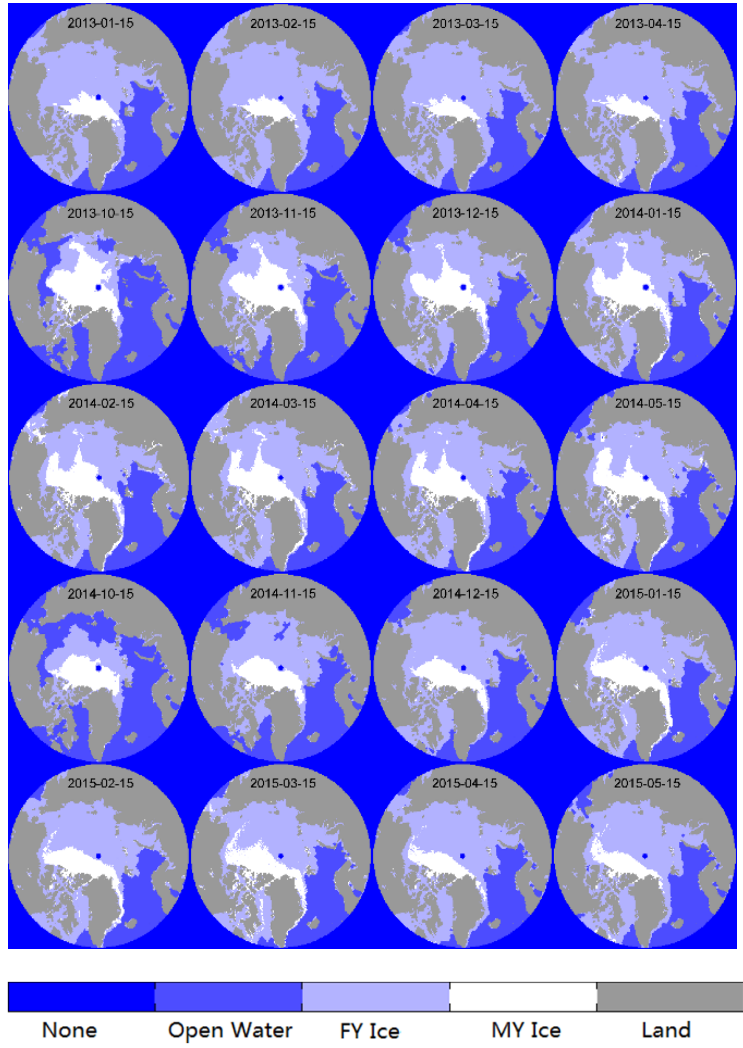

(a)

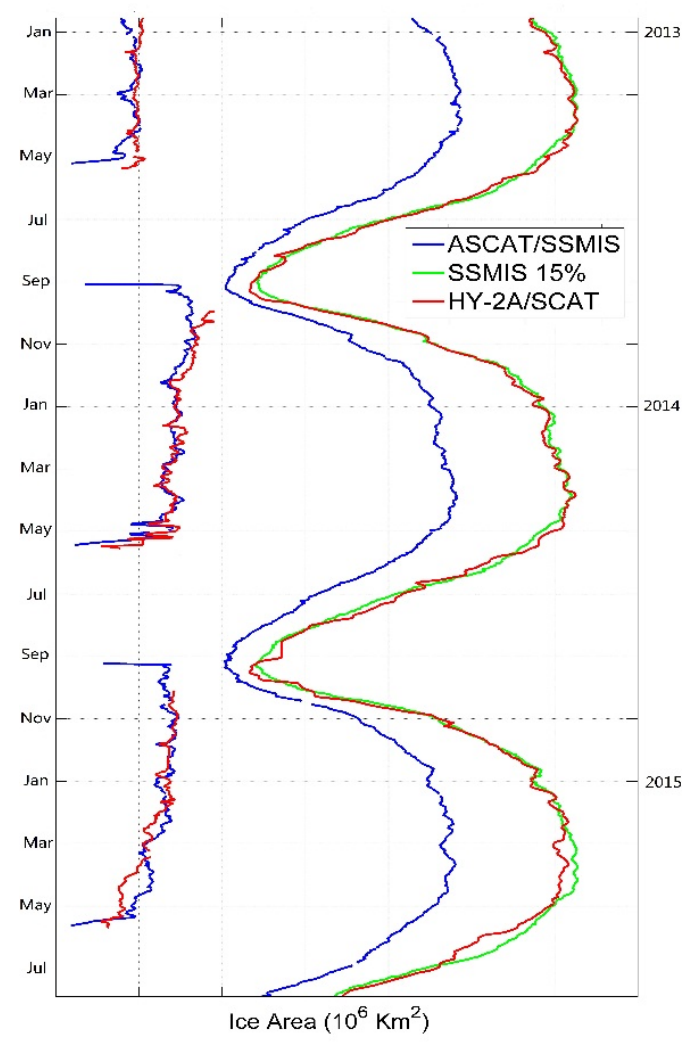

(b)

Figure 10. (a) Maps of the HY-2A/SCAT FY and MY ice, ocean and land on the 15th of each month from January 2013 to July 2015. MY ice is shown in white, FY ice in pike grey and ocean in light blue. (b) Plot of MY ice area and Arctic ice area derived from HY-2A/SCAT (red lines) and ASCAT/SSMIS (blue lines) above $60^{\circ} \mathrm{N}$ latitude, as well as corresponding SSMIS 15\% contour ice area (green line).

\subsection{ASCAT/SSMIS Sea Ice Type Comparison}

After sea ice type identification and classification, we obtain a continuous FY and MY sea ice record of the time period of 2013-2015, which can then be used to analyze the variation trends of the Arctic sea ice with different types. For comparison, the 10-km ASCAT/SSMIS sea ice type products produced using Bayesian approach from the EUMETSAT Ocean and Sea Ice Satellite Application Facility (EUMETSAT OSI SAF) are used [16,17]. 
The trends of the extent of MY ice, the overall ice extent above $60^{\circ} \mathrm{N}$ latitude observed by HY-2A/SCAT and ASCAT/SSMIS, as well as above SSMIS 15\% concentration sea ice extent of the same region are show in Figure 10b. The HY-2A/SCAT observed MY ice shows good agreement with that observed by ASCAT/SSMIS. Meanwhile, similar to Figure 6, HY-2A/SCAT derived total sea ice extent is close to SSMIS 15\% contour sea ice extent at the same region. However, there are considerable differences between the overall sea ice extents. The water-ice edge of the ASCAT/SSMIS ice type product is in fact trained towards SSMIS 30\% ice concentration contour [17], and it also explains the lower coverage of OSI SAF sea ice compared to the HY-2A/SCAT ice cover.

\section{Conclusions}

This paper developed an algorithm to map the sea ice extent over the polar regions using the Ku-band HY-2A/SCAT scatterometer data. Results have shown that HY-2A/SCAT data are capable of effectively discriminating between sea ice and open water using Fisher's linear discriminant analysis method and image processing technology Using an algorithm similar to the one used in [5], arctic sea ice type products are produced using HY-2A derived sea ice extent based on dynamic threshold of the V-pol $\sigma^{0}$ values.

Five microwave parameters are used in this paper: backscatter polarization Ratio $\left(\sigma_{V}^{48} / \sigma_{H}^{41}\right), \mathrm{HH}$ and VV polarized measurements $\left(\sigma_{H}^{41}, \sigma_{V}^{48}\right)$, and the daily standard deviation of dual-polarization $\left(\Delta \sigma_{H}^{41}, \Delta \sigma_{V}^{48}\right)$. The combination of these parameters is proven effective in identifying sea ice versus ocean regions and Arctic sea ice type classification. The HY-2A/SCAT sea ice edge and extent are validated with high-resolution Sentinel-1 SAR imagery and, various sea ice concentration extents derived from SSMIS concentration (NSIDC). The validation results show the HY-2A/SCAT ice extent falls between SSMIS NASA Team 5\% and 30\% ice extent, and total sea ice has a similar seasonal change with SSMIS data. Meanwhile, the HY-2A/SCAT is much more sensitive in detecting the edge of sharp sea ice edge compared with diffusing sea ice edge. In addition, HY-2A/SCAT derived ice type map can provide high confidence MY ice products compared with the OSI SAF operational ASCAT/SSMIS sea ice type product.

In conclusion, this research verifies the capacity of HY-2A/SCAT in monitoring polar sea ice, as well as presents a new polar sea ice extent and type products, which is the extension ice records for the QuikSCAT, OSCAT and ASCAT. Future works will focus mainly on the improvement of algorithm developed in this paper.

Acknowledgments: The authors are grateful to the Chinese Maritime Satellite Application Center, NSIDC and Polar View Website for providing the research data sets. This work is supported by the Shandong Joint Fund for Marine Science Research Center (No. U1406404), the HY-2 Satellite application system-Sea Ice monitoring subsystem (No. OUC20150286), International Science and Technology Cooperation Project of China (contract No. 2011DFA22260) and Open Research Fund of Key Laboratory of Digital Earth Science, Institute of Remote Sensing and Digital Earth, Chinese Academy of Sciences (contract No. 2014LDE009). The authors also thank the anonymous reviewers for their helpful comments.

Author Contributions: Mingming Li processed the data and wrote the manuscript with advice and guidance from Chaofang Zhao. Zhixiong Wang and Yong Zhao contributed to the experiments, and Lijian Shi contributed to the validation of results.

Conflicts of Interest: The authors declare no conflict of interest.

\section{Abbreviations}

The following abbreviations are used in this manuscript:

AMSR-E

AVHRR

ASCAT

CIS

ERS

EUMETSAT

FLDA
Advanced Microwave Scanning Radiometer - Earth Observing System

Advanced Very High Resolution Radiometer

Advanced Scatterometer

Canadian Ice Service (CIS) charts

European Space Agency Remote Sensing Satellite

European Organization for the Exploitation of Meteorological Satellites Fisher's Linear Discriminant Analysis 


$\begin{array}{ll}\text { HY-2A } & \text { The Chinese Hai Yang 2 Satellite } \\ \text { HY-2A/SCAT } & \text { A scatterometer onboard Chinese Hai Yang 2 Satellite } \\ \text { IFREMER } & \text { French Institute of Research for the Exploitation of the Sea } \\ \text { KNMI } & \text { Royal Netherlands Meteorological Institute } \\ \text { MIZ } & \text { the marginal ice zone } \\ \text { MODIS } & \text { Moderate Resolution Imaging Spectroradiometer } \\ \text { NASA } & \text { National Aeronautics and Space Administration } \\ \text { NSCAT } & \text { NASA Scatterometer } \\ \text { NSIDC } & \text { United States National Ice Center } \\ \text { NOAA } & \text { National Oceanic and Atmospheric Administration } \\ \text { NESDIS } & \text { NOAA's Satellite and Information Service } \\ \text { OSCAT } & \text { The Oceansat-2 Ku-band Scatterometer } \\ \text { OLS } & \text { Operational Linescan System } \\ \text { OSI SAF } & \text { the Ocean and Sea Ice Satellite Application Facility } \\ \text { OUC } & \text { Ocean University of China } \\ \text { QuikSCAT } & \text { The Quick Scatterometer (a SeaWinds instrument placed in orbit quickly) } \\ \text { RADARSAT } & \text { Radar Satellite } \\ \text { RL-N } & \text { Remund/Long-NSCAT Algorithm } \\ \text { SAR } & \text { Synthetic Aperture Radar } \\ \text { Seasat-A } & \text { NASA's Sea Satellite }\end{array}$

\section{References}

1. Walsh, J.E. The role of sea ice in climatic variability: Theories and evidence 1. Atmos. Ocean 1983, 21, $229-242$. [CrossRef]

2. Rivas, M.B.; Verspeek, J.; Verhoef, A.; Stoffelen, A. Bayesian sea ice detection with the advanced scatterometer ASCAT. IEEE Trans. Geosci. Remote Sens. 2012, 50, 2649-2657. [CrossRef]

3. Remund, Q.P.; Long, D.G. A decade of QuikSCAT scatterometer sea ice extent data. IEEE Trans. Geosci. Remote Sens. 2014, 52, 4281-4290. [CrossRef]

4. Kwok, R. Annual cycles of multiyear sea ice coverage of the Arctic Ocean: 1999-2003. J. Geophys. Res. Ocean. 2004. [CrossRef]

5. Swan, A.M.; Long, D.G. Multiyear arctic sea ice classification using QuikSCAT. IEEE Trans. Geosci. Remote Sens. 2012, 50, 3317-3326. [CrossRef]

6. Lindell, D.B.; Long, D.G. Multiyear Arctic sea ice classification using OSCAT and QuikSCAT. IEEE Trans. Geosci. Remote Sens. 2016, 54, 167-175. [CrossRef]

7. Remund, Q.P.; Long, D.G. Automated antarctic ice edge detection using NSCAT data. In Proceedings of the 1997 IEEE International, Geoscience and Remote Sensing (IGARSS'97), Remote Sensing-A Scientific Vision for Sustainable Development, Provo, UT, USA, 3-8 August 1997; pp. 1841-1843.

8. Remund, Q.P.; Long, D.G. Sea ice mapping algorithm for QuikSCAT and SeaWinds. In Proceedings of the 1998 IEEE International, Geoscience and Remote Sensing Symposium Proceedings, 1998. (IGARSS'98), Seattle, WA, USA, 6-10 July 1998; pp. 1686-1688.

9. Haarpaintner, J.; Tonboe, R.T.; Long, D.G.; Van Woert, M.L. Automatic detection and validity of the sea-ice edge: An application of enhanced-resolution QuikSCAT/SeaWinds data. IEEE Trans. Geosci. Remote Sens. 2004, 42, 1433-1443. [CrossRef]

10. Remund, Q.P.; Long, D.G. Sea ice extent mapping using Ku band scatterometer data. J. Geophys. Res. Ocean. 1999, 104, 11515-11527. [CrossRef]

11. Yueh, S.H.; Kwok, R.; Lou, S.-H.; Tsai, W.-Y. Sea ice identification using dual-polarized Ku-band scatterometer data. IEEE Trans. Geosci. Remote Sens. 1997, 35, 560-569. [CrossRef]

12. De Abreu, R.; Wilson, K.; Arkett, M.; Langlois, D. Evaluating the use of quikscat data for operational sea ice monitoring. In Proceedings of the 2002 IEEE International Geoscience and Remote Sensing Symposium (IGARSS'02), Ottawa, ON, Canada, 24-28 June 2002; pp. 3032-3033.

13. De Haan, S.; Stoffelen, A. Ice Discrimination Using ERS Scatterometer; EUMETSAT OSI-SAF Technical Report; Eumetsat: De Bilt, The Netherlands; 18; September; 2001.

14. Anderson, H.S.; Long, D.G. Sea ice mapping method for SeaWinds. IEEE Trans. Geosci. Remote Sens. 2005, 43, 647-657. 
15. Rivas, M.B.; Stoffelen, A. New Bayesian algorithm for sea ice detection with QuikSCAT. IEEE Trans. Geosci. Remote Sens. 2011, 49, 1894-1901. [CrossRef]

16. Breivik, L.-A.; Eastwood, S.; Lavergne, T. Use of C-band scatterometer for sea ice edge identification. IEEE Trans. Geosci. Remote Sens. 2012, 50, 2669-2677. [CrossRef]

17. Aaboe, S.; Breivik, L.-A.; Sørensen, A.; Eastwood, S.; Lavergne, T. Global Sea Ice Edge and Type Product User's Manual; OSI-403-b \& EUMETSAT; Norwegian Meteorological Institute: Oslo, Norway, 2015; Available online: http:/ /osisaf.met.no/docs/osisaf_cdop2_ss2_pum_ice-edge-type_v1p3.pdf (accessed on 1 May 2016).

18. Nghiem, S.; Chao, Y.; Neumann, G.; Li, P.; Perovich, D.; Street, T.; Clemente-Colon, P. Depletion of perennial sea ice in the East Arctic Ocean. Geophys. Res. Lett. 2006, 33, 17. [CrossRef]

19. Lindell, D.B.; Long, D.G. Multiyear arctic ice classification using ASCAT and SSMIS. Remote Sens. 2016, 8, 294. [CrossRef]

20. Wang, H.; Zhu, J.; Huang, X.; Chen, C.; Zhao, Y. Assessment of the swell impact on HY-2 SCAT wind products. Proc. SPIE 2014. [CrossRef]

21. Dawei, L.; Hui, S. Evaluating the effect of rain on HY-2A scatterometer measurements. In Proceedings of the 2015 IEEE International Geoscience and Remote Sensing Symposium (IGARSS'05), Milan, Italy, 26-31 July 2015; pp. 4913-4915.

22. Frederick Pearson, I. Map Projections Theory and Applications; CRC Press: Boca Raton, FL, USA, 1990.

23. Snyder, J.P. Map Projections-A Working Manual; US Government Printing Office: Washington, DC, USA, 1987; Volume 1395.

24. Long, D.G.; Early, D.S. Azimuthal modulation of C-band scatterometer over southern ocean sea ice. IEEE Trans. Geosci. Remote Sens. 1997, 35, 1201-1209.

25. Remund, Q.; Early, D.; Long, D. Azimuthal Modulation of Ku-Band Scatterometer-0 over the Antarctic; MERS: Provo, UT, USA; July; 1997.

26. Fukunaga, K. Introduction to Statistical Pattern Classification; Academic Press USA: Boston, MA, USA, 1990.

27. Welling, M. Fisher Linear Discriminant Analysis; Department of Computer Science, University of Toronto: Toronto, ON, Canada, 2005.

28. Duda, R.O.; Hart, P.E.; Stork, D.G. Pattern Classification; John Wiley \& Sons: Hoboken, NJ, USA, 2012.

29. Kunkee, D.B.; Poe, G.A.; Boucher, D.J.; Swadley, S.D.; Hong, Y.; Wessel, J.E.; Uliana, E.A. Design and evaluation of the first special sensor microwave imager/sounder. IEEE Trans. Geosci. Remote Sens. 2008, 46, 863-883. [CrossRef]

30. Adams, R.; Bischof, L. Seeded region growing. IEEE Trans. Pattern Anal. Mach. Intell. 1994, 16, $641-647$. [CrossRef]

31. Russ, J.C. The Image Processing Handbook; CRC Press: Boca Raton, FL, USA, 2015.

32. Godin, R.; Barnett, D. Global: Globoal sea ice limits. In Inventory of Snow Cover and Sea Ice Data; GD-7; Word Data Center for Glaciology: Boulder, CO, USA, 1979; pp. 25-36.

33. Meier, W.N.; Stroeve, J. Comparison of sea-ice extent and ice-edge location estimates from passive microwave and enhanced-resolution scatterometer data. Ann. Glaciol. 2008, 48, 65-70. [CrossRef]

34. Zwally, H.J.; Comiso, J.C.; Parkinson, C.L.; Campbell, W.J.; Carsey, F.D. Antarctic Sea Ice, 1973-1976: Satellite Passive-Microwave Observations; DTIC: Fort Belvoir, VA, USA, 1983.

35. Liu, J.; Curry, J.A.; Wang, H.; Song, M.; Horton, R.M. Impact of declining Arctic Sea ice on winter snowfall. Proc. Natl. Acad. Sci. USA 2012, 109, 4074-4079. [CrossRef] [PubMed]

36. Stroeve, J.C.; Kattsov, V.; Barrett, A.; Serreze, M.; Pavlova, T.; Holland, M.; Meier, W.N. Trends in Arctic Sea ice extent from CMIP5, CMIP3 and observations. Geophys. Res. Lett. 2012. [CrossRef]

(C) 2016 by the authors; licensee MDPI, Basel, Switzerland. This article is an open access article distributed under the terms and conditions of the Creative Commons Attribution (CC-BY) license (http://creativecommons.org/licenses/by/4.0/). 